\title{
Vulnerability and risk in children living with a physical disability
}

Open access

Correspondence:

vheaslip@bournemouth.ac.uk

Vanessa Heaslip and

Jaqui Hewitt-Taylor are senior

lecturers at Bournemouth

University, Dorset

Date of submission

March 252014

Date of acceptance

June 52014

Peer review

This article has been subject to open peer review and checked using antiplagiarism software

Author guidelines

rcnpublishing.com/r/

ncyp-author-guidelines

\author{
Vanessa Heaslip and Jaqui Hewitt-Taylor describe \\ how healthcare professionals can help young people \\ to negotiate risk and increase their independence
}

\begin{abstract}
Children are identified as a vulnerable group in need of a degree of safeguarding. About $6 \%$ of children in the UK have a disability, which can increase their level of vulnerability. How disability is perceived by others may affect the way they work with these young people in coping with life's risks, which may be increased due to the disability. Each individual's perception of the risks and benefits of a given venture varies. Children's nurses work with these young people and their families, aiming to give them maximum autonomy, self-reliance, empowerment and independence in adulthood. This involves risk-taking, as every young person needs to learn from graduated exposure to new experiences, environments, associations and hazards; the chance of harm must be balanced with the disadvantages of over-protection.

\section{Keywords}

Child protection, children's nursing,

child disability, paediatrics, risk management, safeguarding, vulnerability
\end{abstract}

IN 2012, ABOUT 6\% of children in the UK were living with a disability of some kind (Department for Work and Pensions 2012), a significant proportion of which were physical disabilities. Working with children who have a disability is therefore an important part of children's nursing and includes supporting families in preparing their offspring for adult life. The goal is to develop maximum levels of self-determination, control, resilience and independence. A balance has to be struck between enabling children to learn to handle situations in which risk exists and protecting them from harm. This balance can be difficult to achieve, as each individual's perception of disability, risk and benefit varies.

The purpose of this article is to identify perspectives that may be useful when enabling children with disabilities to learn about risk taking. Topics include the ways in which disability is perceived, concepts of vulnerability and risk, the need to protect these children and the variations in each individual's propensity for risk-taking.

\section{Perceptions of disability}

How children with disabilities are regarded is likely to be affected by fundamental perceptions of disability. These include views on the children's involvement in making decisions, including those about risk. The medical and social models of disability are two prevailing concepts.

The medical model perceives disability as a problem caused by a particular impairment or impairments; interventions, therefore, are aimed at correcting these impairments so that the person can fit into society (McKenzie and McAllister 2010).

In contrast, the social model describes ways in which society perpetuates disability through not catering for people with impairments to live 'normally' (Swain et al 2004); this is often related to the provision of physical facilities such as ramps, lifts and accessible toilets, and also to the attitudes and values that society holds and how these may enable or disable people's participation.

Scott (2010) showed that children with disabilities were often given less opportunity than their able-bodied peers to make choices, including the risks they were prepared to take, and to learn about success and failure as a consequence. This social model holds that children with disabilities are put 
at a disadvantage by society's failure to adjust and provide disabled children with the same opportunities as able-bodied peers.

Case study, part 1, illustrates how a situation that contains increased risk for a disabled young person might be viewed. Allowing children with disabilities to make their own decisions about risk helps support them in the process of becoming independent and resilient adults. Such approaches will have to be tailored to each child's developmental stage, environment and particular vulnerabilities.

Vulnerability Definitions of vulnerability usually convey a notion of an individual being at risk of harm from a danger or threat (Heaslip 2013), and are often inferred from some weakness or inadequacy in the person concerned. However, this view is problematic when vulnerability is associated with disability in such a manner that disabilities are equated with weakness, inferiority and dependence on other, stronger people (Batchelor 2006, Willetts 2010).

This portrays people with impairments negatively and fails to acknowledge that, whereas there are undoubtedly some areas in which they are more vulnerable than their peers, they have considerable strengths their peers may not have. It can also perpetuate a focus on what people cannot do, or might be at risk from, rather than on their abilities and potential to achieve.
The social model of disability would suggest that, rather than seeing people's vulnerabilities as a reason for them to be denied the chance to learn about risk, they should be helped to learn to manage their vulnerabilities, to make choices and therefore participate with their peers to the extent they wish. In contrast, the medical model of disability perceives the child's safety and protection needs as paramount, focusing on what they cannot do opposed to what they could do.

Case study, part 2 (page 26), illustrates how the social proposition might work with Jamie who, despite having particular vulnerabilities, wants to try something new that has risks attached.

Common humanity An alternative to perceiving vulnerability as a problem, or as a sign of a person's weakness or disability, is to see it as a common human trait, as everyone is vulnerable at some point in their life (Sellman 2005). Huta and Hawley (2010) suggested that vulnerability and strength coexist and contribute to life satisfaction and self-esteem.

This perspective sees being or becoming vulnerable as an opportunity to explore new ways of dealing with things and to develop new strengths or strategies. Rather than being avoided, our frailties should be acknowledged and used as a part of a positive learning experience through which we can develop the ability to manage weaknesses effectively,

\section{Case study, part 1}

Jamie, not his real name, is 14 years old. He has cerebral palsy and uses a wheelchair. His friends are going out for the day and he wants to go with them. He does not want a parent or carer with him, and his best friend, who often helps Jamie at school, has said that he will make sure that Jamie 'is OK'.

His father is not sure if this is a good idea, as he is uncertain that Jamie's mates are reliable enough to ensure he will be kept safe while he is with them. At the same time, Jamie's father does not want him to miss out on the chance to socialise with his peers.

The medical model of disability might conclude that as Jamie is confined to a wheelchair and requires someone to ensure he is safe, it would be better for him to have an adult with him who could be responsible for meeting his needs.

In contrast, the social model of disability would suggest that part of enabling Jamie to learn to make choices would be to discuss with him how he can assess the benefits and risks of going out with his mates, and the particular measures that should be taken to address these.

Therefore Jamie, his father and his potential companions should talk over what Jamie's needs might be, and ascertain whether the young people feel ready to take the responsibility for assisting Jamie throughout the day. This would include ensuring the availability of his phone so that he could contact his father, and making other contingency plans for any difficulties that might arise.

This process would enable Jamie to learn about weighing up the benefits and risks of the choices he might make and planning ways to manage and overcome risks, and would also give his friends the chance to learn about supporting a disabled peer in their activities. 
and therefore increase our control over our lives (Heaslip 2013).

An important issue in supporting children with disabilities and their families is therefore to explore how their sense of control, choice and decision making can be enhanced to enable them to negotiate their particular disabilities. By this process, positive outcomes of acknowledged impairment can be achieved in that children learn to cope with physical, emotional and social challenges, and through this acquire a sense of autonomy and resilience, which will prepare them for a more satisfying adult life (Gleave and Cole-Hamilton 2012). This could potentially reduce dependence on professional services in the long term, as well as enhanced quality of life for the individual. A crucial issue for many parents and professionals is nonetheless likely to be judging how much and what type of risk is acceptable.

\section{Risk}

Risk can be defined as 'a situation involving exposure to danger, the possibility that something unpleasant may happen' (Soanes and Stevenson 2005). Risks exist because things that are considered to have value are placed in circumstances in which they could be lost. If a venture also carries a potential for gain, the chance of loss may be worth accepting. Risk taking has therefore been defined as the 'voluntary, informed participation in activities or behaviours that contain, or are seen to contain, a significant degree of risk of negative

\section{Case study, part 2}

Jamie has areas in which he is more vulnerable than his friends on a day out. If he receives inadequate assistance, he will be unable to get enough to eat and drink, and he will not be able to move from place to place unaided. One option is to conclude that these vulnerabilities indicate that he should either have a competent adult with him or stay at home.

However, the social model of disability would see the difficulty as an opportunity for Jamie to learn, for example, how best to explain what his needs are, whom he can and cannot trust, and what strategies he can put in place to reduce his vulnerabilities and retain control of situations. This might include: having his mobile phone with him so that he can call his father if necessary; knowing which buses have height-adjustable entrances; and gaining confidence in asking people for assistance. outcomes, along with the potential for some benefit' (Titterton 2010).

The magnitude of the hazard accepted will vary, but the decision about whether or not to persist with the venture depends largely on whether the potential gain is perceived to outweigh the potential loss. In Jamie's case (Case study, part 1), the question is whether he judges that what he may lose by going out with his friends (for example, a degree of comfort and safety) is outweighed by the potential gains (for example, being part of the group and enjoying spending time with his friends and joining in with their activities).

Risk, like vulnerability, can be viewed in different ways. A risk-control perspective sees it as a negative entity, associated with danger and hurt; therefore attempts are made to remove all hazards and adults have the responsibility to shield children from all threat or harm (Loxton et al 2010). If disabled children are seen as being more at risk of damage than others, the risk-control perspective would suggest that greater efforts should be made to protect them.

The difficulty with this view is that taking a chance, and even experiencing some degree of injury or failure, is an important part of children's learning. It enables them to consider and experiment with different ways of negotiating hazardous situations, and to develop the ability to decide which chances they are prepared to take in the future (Bhatt et al 2005).

This is an important part of how the young develop autonomy in and responsibility for their actions (Sharland 2006). If disabled minors are to develop into autonomous, responsible adults, similar to their peers, they have to be able to experience risk and the outcomes of this, and to learn to decide which chances they consider to be worth taking.

In contrast to the risk-control perspective, a risk-taking perspective sees risk as a positive entity, being linked to learning that results in empowerment and self-determination (Loxton et al 2010). The risk-taking perspective would propose that adults' responsibilities include enabling children to learn through taking risks - some of which will be successful and lead to gains - and some of which will inevitably lead to losses.

If disabled children are considered to be at greater risk of hurt than others, a risk-taking approach would focus on enabling them to develop decision making skills and personal risk management strategies, so that they learn to make choices and negotiate the hazards to which they will be exposed throughout their lives, rather than protecting them from the existence of danger. 
Although the focus in discussions of risk is often on physical harm, the chance of emotional, psychological and social harm, such as isolation and exclusion, are equally important. A strategy that involves children avoiding all risk is likely to restrict their experiences and interactions with their peers, and to mean that they experience emotional damage associated with being lonely and isolated (McConkey and Smyth 2003). Therefore, hazards to which a venture exposes a child with impairments may include emotional as well as physical harm, for example insults and prejudiced behaviour.

The counter-argument to protecting them from such situations is that by experiencing these, disabled young people may be enabled to learn to manage them, to overcome exclusion and to develop coping strategies and resilience that will equip them well for adult life.

Box 1 shows some of the dangers Jamie will face if he goes out alone with his friends, and also some of the disadvantages he may face if he does not. Decisions about which risks a disabled child should or should not be exposed to must therefore be accompanied by consideration of any losses with which lack of exposure may be associated. It may be necessary to discern at what point an experience may be helpful, at what point it may become harmful, and how this fits with a professional's duty to protect vulnerable minors.

\section{Influences on perceptions of risk}

Vulnerability and risk are not 'all or nothing' entities. Determining those ventures that are practicable and may constitute good learning experiences for disabled children, and those that constitute a failure to protect them from harm, is far from easy. Individuals all have different priorities, beliefs, values and risk-taking propensities, and some adults as well as children - are more inclined to take chances than others.

This will affect adults' willingness to allow children to engage in risk taking, children's desire to engage in such activities, and each party's perceptions of the dangers and potential gains of any given circumstance (Sandester 2009). It also means that there is no single standard or agreement on the relative risks and benefits. However, by enabling the young to explore what they see as reasonable risk and why, and discussing with them one's own perceptions, they are afforded the opportunity to learn about themselves and their propensity for risk taking, and to understand that people's decisions about risk may vary.

For nurses and others there is a further complication. If the venture ends in loss rather than gain, the natural desire of participants can be to apportion blame, which may be criticism of the professionals involved or even litigation proceedings against them (Bhatt et al 2005, Ball et al 2008, Scott 2010).

The Health and Safety Executive (2012) has clarified that concern with litigation should not be allowed to stand in the way of developmental opportunities. However, such assurances may be insufficient to counter worries in a society that is perhaps becoming increasingly litigious and therefore risk averse. This can affect parents, professionals and provider organisations. It is important that parents and young people are provided with the opportunity and information to enable them to make an informed choice about the risk and that this is documented in the patient's notes.

Disabled children's parents also may fear criticism and accusations of negligent parenting from their peers and from professionals if they allow their children to engage in risk-taking activities. Given the lack of consensus over what constitutes reasonable risk and what is deemed recklessness or negligence, practitioners need to be able to engage in open dialogue with the whole family

\section{Box 1 Balancing the consequences of risk}

The risks that Jamie may encounter if he goes out alone with his friends include:

Being abandoned.

Being injured.

Not being able to eat or drink adequately.

People making fun of him.

Being involved in activities that he would prefer not to be a part of, because he is dependent on his friends.

The risks that Jamie may encounter if he does not go out alone with his friends include:

It will be more difficult for him to be a part of his friendship group.

Reduction in confidence.

Reduction in self-esteem: he may feel different and excluded.

Loss of a chance to learn how to negotiate with others how his needs can be met.

- Loss of a chance to learn how to manage situations and create backup plans for if things go wrong.

- Loss of a chance to learn to manage situations where people make unpleasant comments.

Loss of a chance to develop skills in negotiating what he will and will not be involved in, and to create plans to avoid being coerced to do things he feels uncomfortable with. 
about: risk taking, different perspectives on this and on how children can be enabled to learn about managing risk; what dangers are seen to exist in a given situation; and whether these risks are real and highly likely or only marginally likely.

In the process, the worst-case scenario when going ahead with the venture may be imagined, how this compares with the worst-case scenario if the venture is refused, and how worst-case scenarios might be coped with or avoided. Case study, part 3, shows two of the worst-case scenarios that Jamie and his father identified, their likelihood if the risk was taken and how they might be managed.

Safeguarding children from significant harm is the responsibility of every parent and professional. Nevertheless, there is growing concern in the UK that preoccupation with protecting the young from all danger means that they do not encounter risky situations nor develop the ability to take control of these, judge relative risk and develop resilience (Bhatt et al 2005, Williams-Siegfredson 2005).

Disabled children are at greater risk than their peers of suffering abuse or maltreatment. This requires their parents and those working with them to be particularly vigilant (Department of Health (DH) 2010, Jones et al 2012).

Nonetheless, whereas minors with disabilities often need greater assistance and supportive input than their able-bodied peers, they also need to learn to make judgements about hazardous circumstances and to develop their awareness of themselves, their environment and the consequences of decisions. Safeguarding the vulnerable from immediate trauma should be accompanied by consideration of how they can be preserved from longer term damage, including the emotional, psychological and social harm associated with isolation.

\section{Conclusion}

Adults managing risk in relation to caring for children should aim to provide reasonable protection but also support them in developing skills in coping with their vulnerability and increasing their longer term autonomy, control, safety and resilience. This includes enabling children with a disability to experience risk, learn about danger and develop strategies to negotiate hazardous situations. Perception of the associated benefits and harms is highly individual.

One of the challenges for children's nurses is, therefore, to work with service users, families and one another to agree in each case what level of risk taking is acceptable, and whether the benefits of taking a risk - and the disadvantages of not taking it - outweigh the chance of harm being incurred.

It is therefore vital that safeguarding training includes a discussion of risk as a positive experience to reflect the social model of disability, rather than the medical model, which focuses solely on protection based on the individuals' disability. This includes discussing real and high risks versus imagined or marginal risks, and working out how parents can talk through risk taking with their offpring and help them learn through any consequent unsuccessful activities. It is vital that debate about risk assessment and management strategies should include practitioners, parents and the service users themselves.

\section{Case study, part 3}

\section{Scene 1}

His friends abandon Jamie because they get bored with pushing his chair or want to go somewhere that he cannot get to.

Likelihood: fairly low. Jamie's friends often take him with them when at school, and he has never been abandoned in the playground.

Solution to worst-case scenario: Jamie will have two mobile phones with him, in case he loses one or has it stolen, and will be able to contact his father if he is abandoned. His phone can be easily tracked by the 'find my phone' function, so his father will be able to find him even if he does not know where he is.

\section{Scene 2}

Jamie's friends become involved in illegal activities, such as shoplifting, and when pursued leave Jamie behind.

Likelihood: fairly low. Jamie's friends have not, as far as anyone knows, been involved in this type of activity.

Solution to worst-case scenario: if Jamie becomes aware that his friends are planning to engage in activities he feels uncomfortable with, he can ask his friends to leave him, and telephone his father. If they are in a shopping centre, he can ask a passer-by to contact the security or customer services staff to take him to a safe place to await his father. 
Young people with a disability have to have a voice, and their opinions should be heard in these discussions, as advocated by the DH (2010) and the Children and Families Act 2014, which recognise the need for additional support and emphasis on decision making for vulnerable young people. Some risk is necessary if children are to learn to become resilient and independent adults who can take responsibility for their decisions and actions. Failing to allow minors with a disability to take any chances will reduce their experiences and may increase difficulties in adult life.

As well as exploring how parents can identify and address fears about their child's safety, it may be pertinent for professionals to explore their own views and how their perspectives may influence their responses to disabled children engaging in risk-taking behaviour.

\section{Points for practice}

All children are vulnerable, but disabled children are particularly so. About $6 \%$ of children in the UK are living with a disability of some kind.

- Children's nurses should work with young people and their families to prepare them for adult life. Aims are to maximise autonomy, self-reliance and independence.

- This involves a degree of risk-taking, as the young need to learn from graduated exposure to new experiences, environments, associations and hazards.

- People's perceptions of disability, how it should be managed and the risks and benefits of a given venture vary widely.

The chance of harm must be balanced with the disadvantages of over-protection.

\section{Online archive}

For related information, visit our online archive and search using the keywords

\section{Conflict of interest}

None declared

\section{References}

Ball D et al (2008) Managing Risk in Play Provision: Implementation Guide. Department for Children, Schools and Families, London.

Batchelor D (2006) Vulnerable voices: an examination of the concept of vulnerability in relation to student voice. Educational Philosophy and Theory. 38, 6, 787-800.

Bhatt US et al (2005) Understanding the Effect of Risk Aversion on Risk. Thirty-eighth Hawaii International Conference on System Sciences, Honolulu, Hawaii HI.

Department for Work and Pensions (2012) Disability Facts and Figures. tinyurl.com/8zo9ooa (Last accessed: November 13 2014.)

Department of Health (2010) Equity and Excellence: Liberating the NHS. DH, London.

Gleave J, Cole-Hamilton I (2012) A World Without Play. Play England, London.
Health and Safety Executive (2012) Children's

Play and Leisure: Promoting a Balanced Approach. HSE, London.

Heaslip V (2013) Understanding vulnerability. In Heaslip V, Ryden J (Eds) Understanding Vulnerability: A Nursing and Health Care Approach. Wiley Blackwell, Oxford.

Huta V, Hawley L (2010) Psychological strengths and cognitive vulnerabilities: are they two ends of the same continuum or do they have independent relationships with well-being and ill-being? Journal of Happiness Studies. $11,1,71-93$.

Jones L et al (2012) Prevalence and risk of violence against children with disabilities: a systematic review and meta-analysis of observational studies. The Lancet. 380 9845, 899-907.

Loxton J et al (2010) Risk. In Hothersall S, Maas-Lowit M (Eds) Need, Risk and Protection in Social Work Practice. Learning Matters,

Sage, London.
McKenzie F, McAllister H (2010) The roots of bio-medical diagnosis. In Grant G, et al (Eds) Learning Disability: A Lifecycle Approach. Second edition. McGraw-Hill Education, Maiden head.

McConkey R, Smyth M (2003) Parental perceptions of risks with older teenagers who have severe learning difficulties contrasted with the young people's views and experiences. Children and Society. 17, 1, 18-31.

Sandester EBH (2009) Risky play and risk management in Norwegian preschools: a qualitative observational study. Safety Science Monitor. 13, 1, 2 .

Scott R (2010) The Health Benefits of Play and Physical Activity for Disabled Children and Young People. KIDS, London.

Sellman D (2005) Towards an understanding of nursing as a response to human vulnerability. Nursing Philosophy. 6, 1, 2-10.
Sharland E (2006) Young people, risk taking and risk making: some thoughts for social work. Qualitative Social Research. 7, 1, Art. 23.

Soanes C, Stevenson A (Eds) (2005) Oxford Dictionary of English. Oxford University Press, Oxford.

Swain J et al (2004) Disabling Barriers

- Enabling Environments. Second edition. Sage, London.

Titterton M (2010) Positive Risk Taking. Health and Life for Everyone, Edinburgh. Williams-Siegfredson J (2005) Run the Risk. tinyurl.com/np42xs8 (Last accessed: November 132010 .

Willetts C (2010) People with learning difficulties - issues of vulnerability. In Brown $\mathrm{K}$ (Ed) Vulnerable Adults and Community Care. Learning Matters, Sage, London. 